\title{
Erratum to: An investigation of future fuel load and fire weather in Australia
}

\author{
Hamish Clarke ${ }^{1,2,3}$ • Andrew J. Pitman ${ }^{1}$ • Jatin Kala ${ }^{1,4}$. \\ Claire Carouge $^{1}$ - Vanessa Haverd ${ }^{5}$. Jason P. Evans ${ }^{1}$
}

Published online: 3 October 2016

C) Springer Science+Business Media Dordrecht 2016

\section{Erratum to: Climatic Change \\ DOI 10.1007/s10584-016-1808-9}

It needs to be acknowledged that during the preparation of this article, author Jatin Kala spent an equal amount of time at his current employer:

School of Veterinary and Life Sciences, Environmental and Conservation Sciences, Murdoch University, 6150, Western Australia, Australia

The online version of the original article can be found at http://dx.doi.org/10.1007/s10584-016-1808-9.

Hamish Clarke

hamishc@uow.edu.au

1 ARC Centre of Excellence for Climate System Science and Climate Change Research Centre, University of New South Wales, Sydney 2052, Australia

2 Climate and Atmospheric Science Branch, NSW Office of Environment and Heritage, Box 3720, Parramatta, PO, Australia

3 Centre for Environmental Risk Management of Bushfires, University Wollongong, Northfields Avenue, Wollongong 2522, Australia

4 School of Veterinary and Life Sciences, Environmental and Conservation Sciences, Murdoch University, 6150 Western Australia, Australia

5 CSIRO Marine and Atmospheric Research, GPO Box 664, Canberra 2601, Australia 